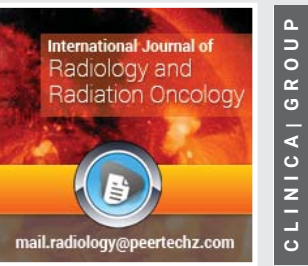

\title{
Successfull multidisciplinary management of giant nasal fibromyxoma: Case report and literature review
}

\author{
Ismail Essadi', Issam Lalya ${ }^{2 \star}$, Mohamed Kaakoua ${ }^{1}$, Haddou \\ Aammar ${ }^{3}$, Mustapha Alaoui ${ }^{4}$ and Mohamed Lakouichmi ${ }^{5}$
}

${ }^{1}$ Medical Oncology, Ibn Sina Military Hospital, Faculty of Medicine and Pharmacy Mohamed VI, Caddy Ayyad University, Marrakesh, Morocco

${ }^{2}$ Radiation Oncology, Mohammed VI Oncology Hematology Center , Faculty of Medicine and Pharmacy Mohamed VI, Caddy Ayyad University, Marrakesh, Morocco

${ }^{3}$ ENT, Ibn Sina Military Hospital, Faculty of Medicine and Pharmacy Mohamed VI, Caddy Ayyad University, Marrakesh, Morocco

${ }^{4}$ Peripheral Vascular Surgery, Ibn Sina Military Hospital, Faculty of Medicine and Pharmacy, Caddy Ayyad University, Marrakesh, Morocco

${ }^{5}$ Maxillofacial Surgery, Ibn Sina Military Hospital, Faculty of Medicine and Pharmacy, Caddy Ayyad University, Marrakesh, Morocco

Received: 17 April, 2020

Accepted: 12 May, 2020

Published: 13 May, 2020

*Corresponding author: Issam Lalya, Professor, Radiation Oncology, Mohammed VI Oncology Hematology Center , Faculty of Medicine and Pharmacy Mohamed VI, Caddy Ayyad University, Marrakesh, Morocco, Tel: (+212) 661572770; E-mail: issamlalya@yahoo.fr

Keywords: Fibromyxoma; Nasal; Arterial embolization; Resection; Multidisciplinarity

https://www.peertechz.com

Check for updates

\section{Abstract \\ Introduction: Fibromyxomas are very rare benign tumors of the head and neck region. They are characterized by the replacement of normal bone by a fibrous cellular stroma. These tumors are slow-growing benign lesions, which may cause extensive local destruction with a tendency to recurrence after surgical excision. \\ Case presentation: We report the case of a 52-years-old Moroccan female, diagnosed with giant nasal fibromyxoma. This case was successfully managed by a multidisciplinary team, with complete resection of the tumor after arterial embolization, allowing a good functional and locoregional control. To our knowledge, this kind of multidisciplinary approach has had never been described in the literature, with successful results. \\ Conclusion: Nasal fibromyxoma, represents a rare situation. Advanced forms require multidisciplinary management, involving embolization to reduce bleeding and unsightly complications from extensive surgery.}

\section{Introduction}

Fibromyxomas are very rare tumors affecting the head and neck region [1]. They are benign tumors characterized by local aggressivity, with a poor possibility to metastatic evolution $[1,2]$. These tumors usually occur in the second or third decades, rarely in children or adults after 50 years old [3]. Imaging plays a pivotal role in the noninvasive diagnosis and characterization of these tumors, providing information about the location of these tumors, their extension and invasion of adjacent structures [4]. Multidisciplinary management is the guarantee of optimal care, which can allow a curability status [5]. Advanced forms require multidisciplinary management, involving embolization to reduce bleeding and unsightly complications from extensive surgery. We report here a case of giant nasal fibromyxoma successfully managed thanks to the intervention of a multidisciplinary team that performed an arterial embolization followed by a complete non-mutilating resection, with good functional and locoregional control. 


\section{Case presentation}

52-years-old Moroccan female, without any specific medical history (trauma, fever, dental trouble or nasal obstruction), presented at the Military Hospital AVICENNE Marrakesh-Morocco, with progressive swelling and painless right paranasal region appeared since 2 years (Figure 1). The evolution was marked by the appearance of a pain interesting the right hemiface to the palpation and the attempts of nasal aspiration. This pain became spontaneous afterwards. The general examination was within the normal limits. The patient also reports the appearance of phonatory problems and the inability to breathe nasally. The Visual analog pain scale gave a score of $5 / 10$, which was calmed by analgesics. Local examination revealed a regular swelling of the nasal mucosa on the right, painful not allowing access to the naso-fibroscope. This swelling extended to the ipsilateral sub-palpebral region. No nasal invasion was observed and her dentition was normal. A biopsy was performed with anatomopathological study. The result after The immunohistochemical complement was in favor of fibromyxoma. Facial CT scan showed a mass measuring $4 \mathrm{X} 3 \mathrm{~cm}$ with the invasion of the two nasal fossae and the right maxillary sinus. This mass describes an intimate contact with the sphenoid bone with the beginning of lysis of the latter (Figure 2). We also note a rapid enhancement by the contrast product, testifying to the hypervascular nature of this mass. The complement by the MRI allowed eliminating a probable vascular or nervous extension especially towards the optical chiasma (Figure 3). An angiogram performed 24 hours before the exeresis surgery, identified the terminal branch of the internal maxillary artery responsible for the vascularization of this mass (Figure 4). An embolization of this branch was performed to prepare the excision surgery. A monobloc resection was performed 24 hours after embolization minimizing the risk of bleeding and improving dissection possibilities (Figure 5). The anatomopathological study of the mass confirmed the diagnosis of Fibromyxoma, and determined the non-invasiveness of the resection limits. The patient was discharged from the hospital 3 days after the intervention with disappearance of the pains and phonatory disorders. After a follow-up of 12 months, there were no signs of locoregional recurrence or postoperative complications.

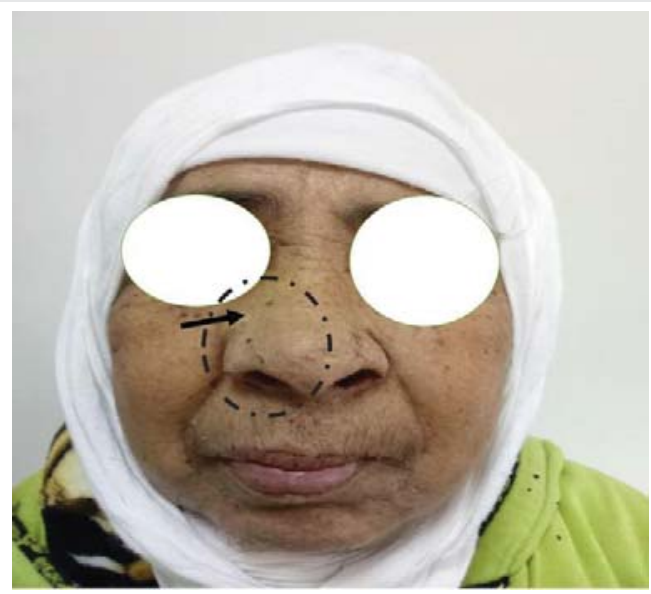

Figure 1: Right paranasal mass.

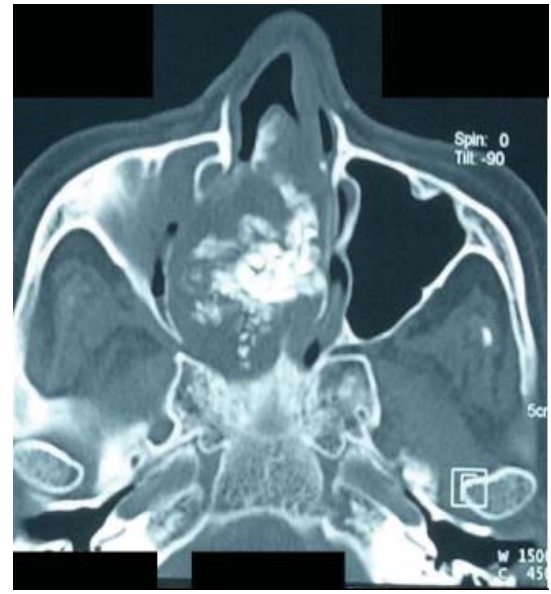

Figure 2: Facial CT scan showing a mass measuring $4 X 3 \mathrm{~cm}$ with invasion of the two nasal fossae and the right maxillary sinus.

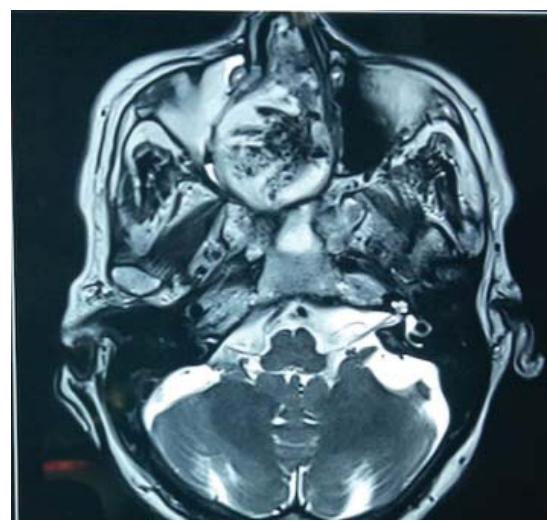

Figure 3: Facial MRI showing a giant mass filling the nasal fossae and the right maxillary sinus.

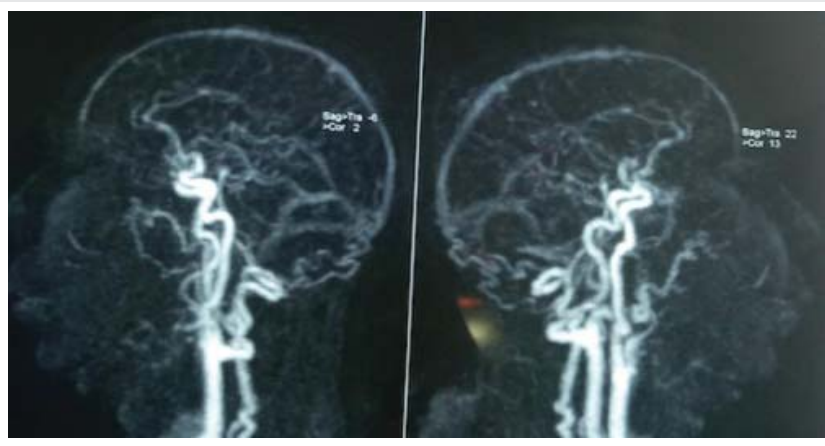

Figure 4: Angiogram identifying the terminal branch of the internal maxillary artery responsible for the vascularization of the mass.

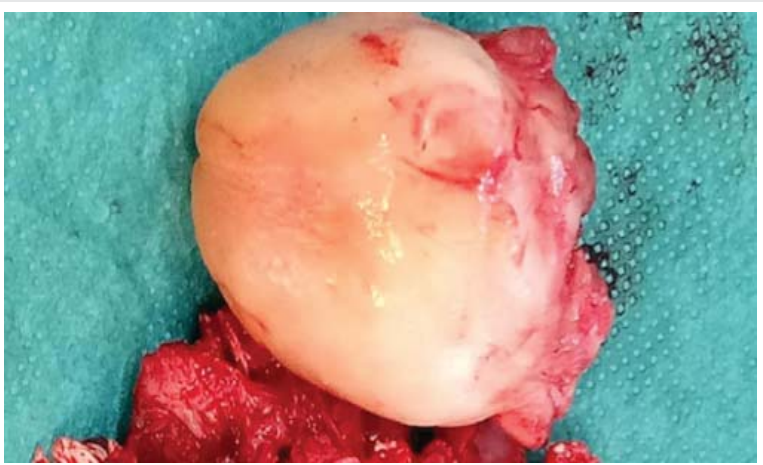

Figure 5: Macroscopic appearance of the mass after resection. 


\section{Discussion}

Fibromyxoma is a rare benign or low-grade soft-tissue tumor, related to fibro-osseous lesions and involves the paranasal sinuses $[1,2]$. These tumors are characterized by benign evolution, but they can in some situations have a locoregional destructive behavior [3]. Clinically they can be incidentally discovered when imaging is performed for another indication, or may become symptomatic in relation to a mass effect of the tumour on adjacent structures $[5,6]$. In our case the diagnosis was made after symptomatic mass, growing for almost 3 years. It's common to find focal areas of bone destruction [7]. MRI is the first-line examination for diagnosis and pre-surgical assessment $[7,8]$. It shows a welldefined oval lesion, showing a high signal intensity under T2WI, a low signal intensity under T1WI and a significant enhancement after gadolinium administration [8]. The lesion often contains hypo-intense fibrous septa [9]. In our case, the radiological appearance on MRI was not typically in favor of fibromyxoma. Hypervascularity and local invasive behavior required preoperative biopsy guided by nasal endoscopy Histopathologically, Fibromyxoma has odontogenic and mesenchymal origin, probably arising from connective tissue of dental papilla, hence called odontogenic myxoma [10]. Fibromyxomas are in the form of unencapsulated and welldefined masses [11]. Their consistency varies from firm to gelatinous depending on the amount of collagen / myxoid stroma they contain. These are hypocellular lesions composed of slender spindle and stellate cells with a discrete cytoplasm $[10,11]$. The immunohistochemical complement is not of great help, but allows in some cases to refine the diagnosis. The tumor cells are positive for vimentin and laminin [12]. In this case the anatomopathological diagnosis was simple to the morphological study, with an immunohistochemical complement which confirmed the diagnosis. Complete surgical resection is mandatory to treat fibromyxoma. This resection may also allow to avoid any locoregional reccurence [13]. Complete surgical resection of giant fibromyxoma is difficult $[13,14]$. The dural or orbital invasion and the hypervascular character can make this resection laborious. Thus, complete removal of this type of injury has always been a challenge. As reported by Wang et al., To avoid recurrence, it would seem necessary to remove the outer lamella from the tumor and drill a pathological bone with a diamond bur until it reaches a smooth, healthy bone with a less fragile consistency [14]. Endoscopic resection in giant fibromyxomas could result in fragmented resection, increasing the risk of recurrence. Traditionally, extranasal or microscopic techniques have been described to achieve complete resection [15]. However, recent studies have suggested an endoscopic resection technique, with improved endoscopes and instruments, increased surgical experience, advanced techniques (eg, "four-handed technique"), and routine use of navigation systems [16]. In our context it seems that conventional surgery remains the most appropriate technique. In the last 20 years, preoperative embolization of blood vessels in large tumors of the head and neck field has yielded encouraging results. It's seems to be the standard of care in some giant paragangliomas or Juvenil nasa tumors. The most important risk when embolising the orbital region is the occlusion of the central retinal artery, which is a terminal vessel and results in blindness of the patient [17]. The purpose of this embolization is to allow a slight reduction in tumor volume and better control of bleeding during surgery [18]. These two elements can guarantee better chances for a complete resection of giant fibromyxomas. To the best of our knowledge there is no publication describing this therapeutic protocol (arterial embolization followed by surgery) in advanced nasal fibromyxomas. Our case was managed by a multidisciplinary team having performed arterial embolization 24 hours before surgery, with complete resection of the tumor.

\section{Conclusion}

Nasal fibromyxoma is a rare benign tumor. Clinical, radiological and histological data should all be taken into consideration to better establish a differential diagnosis with other fibro-osseous, benign or malignant tumors, and a preoperative biopsy should always be performed as far as possible. For giant tumors, the multidisciplinary approach including preoperative arterial embolization should be considered as part of standard of care, to ensure complete resection with less risk of complications

\section{Declarations}

"Written informed consent was obtained from the patient for publication of this case report and any accompanying images. A copy of the written consent is available for review by the Editor-in-Chief of this journal."

\section{Author's contributions}

All authors read and approved the final manuscript.

\section{Acknowledgements}

We sincerely thanks Mrs Souad TADLAOUI for her assistance.

\section{References}

1. DeFatta RJ, Verret DJ, Ducic Y, Carrick K (2006) Giant Myxomas of The Maxillofacial Skeleton and Skull Base. Otolaryngol Head Neck Surg 134: 931 935. Link: https://bit.ly/2YXXtMX

2. Yin H, Cai BW, An HM, You C (2007) Huge Primary Myxoma of Skull Base: A report of an uncommon case. Acta Neurochir (Wien)149: 713-717. Link: https://bit.ly/3bwe39g

3. Zhang L, Zhang M, Zhang J, Luo L, Xu Z, et al. (2007) Myxoma of The Crania Base. Sur Neurol 68: 22-28. Link: https://bit.ly/2T0wCfq

4. Indharty S (2015) Review of Nasa Fibromyxoma: Aggressive Behaviour? (Case Report). Bali Med J 4: 132-135. Link: https://bit.ly/2xY8Edn

5. Dhawan S, Agarwal N (2014) Myxoma of nose and paranasal sinuses. Curr Med Res Pract 4: 286-288. Link: https://bit.ly/2ArGYi9

6. Yucel Ekici N, Yucel G, Haytoğlu S, Küllahci Ö (2018) Giant Congenital Soft Tissue Sinonasal Fibromyxoma of the Nose in a Newborn Baby. J Craniofac Surg 29: 2114-2115. Link: https://bit.ly/3619x1p

7. Shivakumar GC, Sahana S (2010) Fibromyxoma of the maxilla: a case report Int J Med Sci 9: 36-41. 
8. Berry S, Puri R (2006) Fibromyxoma of the maxilla. Otolaryngology 135 : 330 331.

9. Shah A1, Lone P, Latoo S, Ahmed I, Malik A, et al. (2011) Odontogenic myxoma of the maxilla: a report of a rare case and review on histogenetic and diagnostic concepts. Natl J Maxillofac Surg 2: 189-195. Link: https://bit.ly/3fMhID4

10. Dietrich EM, Papaemmanouil S, Koloutsos G, Antoniades H, Antoniades K (2011) Odontogenic fibromyxoma of the maxilla: a case report and review of the literature. Case Reports in Medicine 2011: 5. Link: https://bit.ly/2YTEYJA

11. Prasad Reddy GS, Surya Kumar B, Muppa R, Regonda SK, Kumar TVS H (2013) Odontogenic Fibromyxoma of Maxilla: A Rare Case Report. Case Rep Dent 2013: 345479. Link: https://bit.ly/3dHAABC

12. Speight PM, Carlos R (2006) Maxillofacial fibro-osseous lesions. Curr Diagn Pathol 12: 1-10. Link: https://bit.ly/2ZOnGdM

13. Castelnuovo P, Valentini V, Giovannetti F, Bignami M, Cassoni A, et al. (2008) Osteomas of the maxillofacial district: endoscopic surgery versus open surgery. J Craniofac Surg 19: 1446-1452. Link: https://bit.ly/3dHdyec
14. Wang $\mathrm{H} 1$, Sun $\mathrm{X}$, Liu Q, Wang J, Wang D (2014) Endoscopic resection of sinona- sal ossifying fibroma: 31 cases report at an institution. Eur Arch otorhinolaryngol 271: 2975-2982. Link: https://bit.ly/2WqyKz1

15. Savastano M, Guarda-Nardini L, Marioni G, Staffieri A (2007) The bi- coronal approach for the treatment of a large frontal sinus osteoma. A technical note. Am J otolaryngol 28: 427-429. Link: https://bit.ly/2ArlFw1

16. Pagella F, Pusateri A, Matti E, Emanuelli E (2012) Transnasal endoscopic approach to symptomatic sinonasal osteomas. Am J Rhinol Allergy 26: 335339. Link: https://bit.ly/2WtEnwx

17. Smith TP (2006) Embolization in the external carotid artery. J vasc interv radio 17: 1897-1913. Link: https://bit.ly/2WPwKzA

18. Kansal A, Srinet P, Manes RP (2016) Direct Tumor Embolization of Sinonasal Unclassified Spindle Cell Sarcoma with Onyx. J Neurol Surg Rep 77: e139e143. Link: https://bit.ly/3bnsj41

\section{Discover a bigger Impact and Visibility of your article publication with}

\section{Peertechz Publications}

\section{Highlights}

* Signatory publisher of ORCID

- Signatory Publisher of DORA (San Francisco Declaration on Research Assessment)

- Articles archived in worlds' renowned service providers such as Portico, CNKI, AGRIS, TDNet, Base (Bielefeld University Library), CrossRef, Scilit, J-Gate etc.

* Journals indexed in ICMJE, SHERPA/ROMEO, Google Scholar etc.

* OAI-PMH (Open Archives Initiative Protocol for Metadata Harvesting)

* Dedicated Editorial Board for every journal

* Accurate and rapid peer-review process

* Increased citations of published articles through promotions

* Reduced timeline for article publication

Submit your articles and experience a new surge in publication services (https://www.peertechz.com/submission).

Peertechz journals wishes everlasting success in your every endeavours.

Copyright: @ 2020 Essadi I, et al. This is an open-access article distributed under the terms of the Creative Commons Attribution License, which permits unrestricted use distribution, and r eproduction in any medium, provided the original author and source are credited.

Citation: Essadi I, Lalya I, Kaakoua M, Aammar H, Alaoui M, et al. (2020) Successfull multidisciplinary management of giant nasal fibromyxoma: Case report and literature review. Int J Radiol Radiat Oncol 6(1): 007-010. DOI: https://dx.doi.org/10.17352/ijrro.000037 